\title{
Refractive index determination of SiGe using reactive ion etching/ellipsometry: application of the depth profiling of the Ge concentration
}

Citation for published version (APA):

Kroesen, G. M. W., Oehrlein, G. S., Frésart, de, E., \& Scilla, G. J. (1992). Refractive index determination of SiGe using reactive ion etching/ellipsometry: application of the depth profiling of the Ge concentration. Applied Physics Letters, 60(11), 1351-1353. https://doi.org/10.1063/1.107314

DOI:

$10.1063 / 1.107314$

Document status and date:

Published: 01/01/1992

Document Version:

Publisher's PDF, also known as Version of Record (includes final page, issue and volume numbers)

Please check the document version of this publication:

- A submitted manuscript is the version of the article upon submission and before peer-review. There can be important differences between the submitted version and the official published version of record. People interested in the research are advised to contact the author for the final version of the publication, or visit the DOI to the publisher's website.

- The final author version and the galley proof are versions of the publication after peer review.

- The final published version features the final layout of the paper including the volume, issue and page numbers.

Link to publication

\footnotetext{
General rights

- You may freely distribute the URL identifying the publication in the public portal. follow below link for the End User Agreement:

www.tue.nl/taverne

\section{Take down policy}

If you believe that this document breaches copyright please contact us at:

openaccess@tue.nl

providing details and we will investigate your claim.
}

Copyright and moral rights for the publications made accessible in the public portal are retained by the authors and/or other copyright owners and it is a condition of accessing publications that users recognise and abide by the legal requirements associated with these rights.

- Users may download and print one copy of any publication from the public portal for the purpose of private study or research.

- You may not further distribute the material or use it for any profit-making activity or commercial gain

If the publication is distributed under the terms of Article $25 \mathrm{fa}$ of the Dutch Copyright Act, indicated by the "Taverne" license above, please 


\title{
Refractive index determination of SiGe using reactive ion etching/ellipsometry: Application for the depth profiling of the Ge concentration
}

\author{
G. M. W. Kroesen, G. S. Oehrlein, E. de Frésart, and G. J. Scilla \\ IBM Research Division, Thomas J. Watson Research Center, Yorktown Heights, New York 10598
}

(Received 1 May 1991; accepted for publication 5 January 1992)

The complex refractive index at a wavelength of $632.8 \mathrm{~nm}$ of strained epitaxial SiGe layers on silicon substrates has been determined as a function of the germanium content using in situ ellipsometry during reactive ion etching. The germanium concentration was obtained from Rutherford backscattering. These index values are used to invert the ellipsometry equations. Using this principle, the Ge concentration depth profile of an unknown SiGe structure can be determined from an in situ ellipsometry measurement sequence that is taken while the unknown sample is being etched.

Recently, the properties of alloys of silicon and germanium have become the subject of a great deal of interest. ${ }^{1}$ Electronic devices incorporating strained epitaxial films of that material can be much faster than devices that exclusively use silicon. ${ }^{2}$ The films may be grown by molecular beam epitaxy (MBE) or by ultrahigh vacuum chemical vapor deposition (UHVCVD). ${ }^{3}$ Since the 1960 's, several studies of the optical parameters of SiGe alloys have been performed. ${ }^{4}$ In all cases, however, the material was fully relaxed, and therefore the lattice constant was different from strained epitaxial material. Experimental data is not available for the complex index of refraction of strained epitaxial films of SiGe on silicon substrates.

In this letter, we describe ellipsometric studies of strained epitaxial films on silicon substrates. For strained epitaxial $\mathrm{SiGe}$ layers on $\mathrm{Si}$, the film thickness cannot exceed a certain critical value, which depends on the $\mathrm{Ge}$ content. ${ }^{1}$ Above this critical thickness the film will develop a large number of defects, and the material may have totally different electrical and optical properties. Therefore, all measurements will have to be performed on thin films up to about $100 \mathrm{~nm}$ thick.

An ellipsometric measurement yields $\Psi$ and $\Delta$, which are the intensity ratio and the phase difference induced between the $p$ and $s$ directions (parallel and perpendicular to the plane of incidence, respectively) when quasi-monochromatic light reflects at a surface. ${ }^{5}$ The refractive index of the silicon substrate is known $(388-0.019 i){ }^{6}$ The unknowns are the real and imaginary part of the refractive index and film thickness. The number of unknowns is larger than the number of measurement data. Therefore, for determination of the optical parameters of the film material, one of the physical parameters has to be changed or modulated, and ellipsometry measurements have to be taken during that change. A frequently used modulation parameter is the wavelength. Reports of spectroscopic cllipometry performed on SiGe alloys have been published. ${ }^{7}$ However, it is difficult to extract the optical parameters of the material unambiguously from a spectrum obtained from an epitaxial film. In this work, we have chosen the film thickness as the parameter to modulate. Since it was not possible to perform in situ ellipsometry on the samples during growth, we changed the film thickness by gradually removing material from the sample surface using reactive ion etching (RIE).

The experiments were performed in a rcactor cquipped with a 12-in. water-cooled quartz-covered rf-powered (13.56 MHz) electrode. The $\mathrm{CF}_{4}$ gas was fed through a MKS mass flow controller. The flow rate was kept at 100 sccm at all times. A throttle valve in the pumping line to a $500 \mathrm{\ell} / \mathrm{s}$ Leybold turbomolecular pump kept the pressure at $25 \mathrm{mT}$ Torr in all experiments. The wafer was placed on the powered electrode. The power level was kept comparatively low $(50 \mathrm{~W})$ in order to minimize the surface modification of the material, since these could affect the ellipsometry measurements. Since the measurement rate of the cllipsometer is limited to about $1 / \mathrm{s}^{-1}$, the low power level also offers the advantage of a large number of data points. The ellipsometer used in these experiments is an automated rotating compensator ellipsometer in the polarizer-samplecompensator-analyzer (PSCA) configuration. ${ }^{8}$ The polarizer is a Rochon prism, the analyzer a Glan-Thomson prism. The compensator is unsupported mica. The data are taken by a 16-bit ADC located in an Analog Device RTI850 interface card in an IBMPC/AT. A He-Ne laser

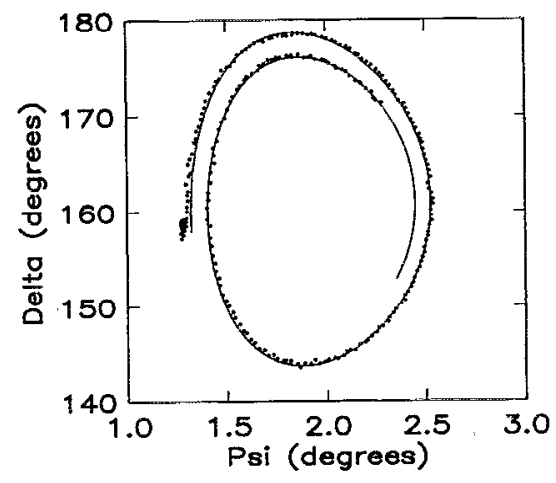

FIG. 1. The $\Psi-\Delta$ contour generated by an in situ ellipsometry measurement during the reactive ion etching of a strained epitaxial homogeneous SiGe film on a silicon substrate. 
( $632.8 \mathrm{~nm}$ ) is used as a light source, and a photomultiplier tube as a detector. The angle of incidence was chosen between $74.0^{\circ}$ and $75.0^{\circ}$.

The SiGe layers were grown on 125 -mm-diameter $\mathrm{Si}(100)$ wafers by the UHV/CVD (ultrahigh vacuum chemical vapor deposition) technique. ${ }^{3,9}$

Figure 1 shows an example of the $\Psi-\Delta$ plot which is recorded during the etching of a homogeneous SiGe film. The points denote the measurement data, the full curve represents a simulation based on a single-layer model. The parameter that has been changed to yield the simulated profile is the film thickness. The complex refractive index has been kept constant. The agreement between simulation and measurement is quite good, so the single-layer model offers a good description of the etching film on the substrate: the material is indeed homogeneous. By analyzing a number of $\Psi-\Delta$ curves corresponding to films of different germanium content, the complex refractive index of the material as a function of wavelength can be obtained. In Fig. 2, the real (a) and the imaginary (b) part of the refractive index of the strained epitaxial material is plotted
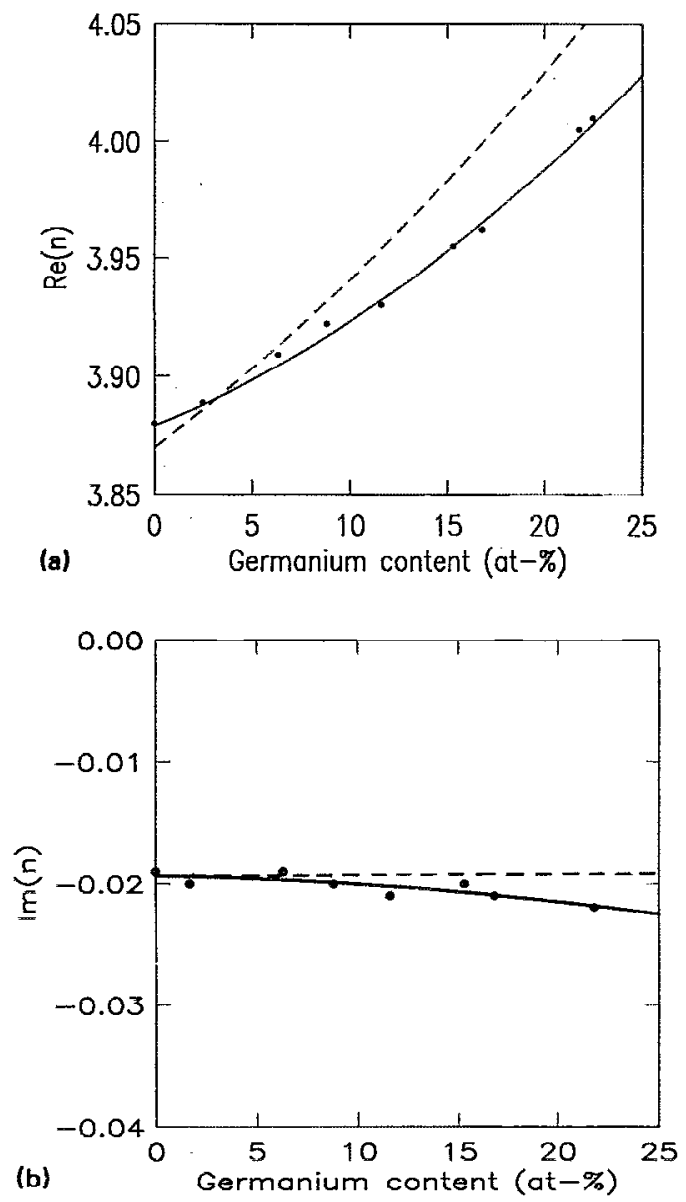

FIG. 2. (a) The real part of the refractive index of strained epitaxial SiGe films on a silicon substrate as a function of the germanium content. (b) The imaginary part of the refractive index of strained epitaxial SiGe films on a silicon substrate as a function of the germanium content. In both graphs, the full curve represents our results for the strained films, and the dashed curve corresponds to the values for fully relaxed material as reported in the literature.

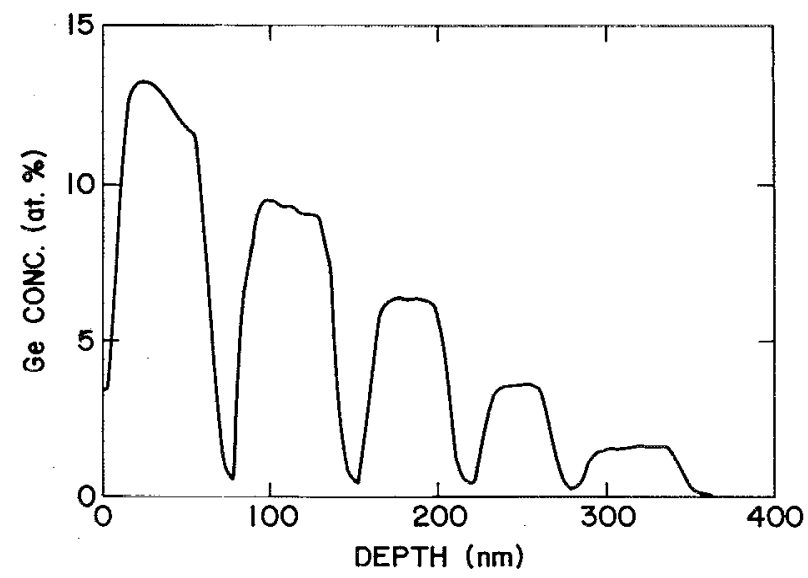

FIG. 3. The depth profile of the germanium content of a superlattice structure as measured with SIMS.

versus the germanium content. The germanium concentration was obtained with Rutherford backscattering spectroscopy. The calibration procedure which was used to obtain Figs. 2(a) and 2(b) will be described in detail elsewhere ${ }^{10}$ In Figs. 2(a) and 2(b) the dashed line corresponds to the values found by Humlicek et al. for fully relaxed material. ${ }^{11}$ The density for fully relaxed material is less than for strained material, which by itself would predict a lower refractive index for relaxed material. The measurements suggest the opposite. It is therefore likely that the refractive index is largely determined by the strain, not by the material density. In the $\mathrm{Ge}$ concentration range investigated in this work the imaginary part of the refractive index hardly depends on the germanium content, i.e., the absorption of the material is constant. The real part of the refractive index $n$ is fitted with a parabola: $n=A x^{2}+B x+C$, where $A=1.0395 \times 10^{-4}, B$ $=3.3733 \times 10^{-3}, C=3.87972$, and $x$ represents the atomic Ge percentage. This formula can be used up to atomic germanium concentrations of about $25 \%$.

Since all RIE-ellipsometry measurements were performed at the same angle of incidence, a possible anisotropy of the refractive index will not be detected. Epitaxial SiGe films on Si substrates are known to exhibit a large stress in the plane of the film, and much less stress in the perpendicular direction. The presence of stress may influence the value of the refractive index. One can therefore not exclude that the epitaxial films do show anisotropy with respect to the refractive index. This issue will be addressed in a future publication. ${ }^{10}$

With the relation between the real and the imaginary part of the refractive index known [Figs. 2(a) and 2(b)], the ellipsometric equations can be inverted. If an unknown SiGe structure is etched, the $\Psi-\Delta$ contour may be interpreted in terms of a Ge concentration profile in the following way: Each of the pair of adjacent $\Psi-\Delta$ points corresponds to the removal of a very thin layer (roughly 0.1 $\mathrm{nm}$ ). Throughout this thin layer the refractive index can be assumed constant. Since the material is known to be SiGe, the imaginary part of the refractive index is known as soon 


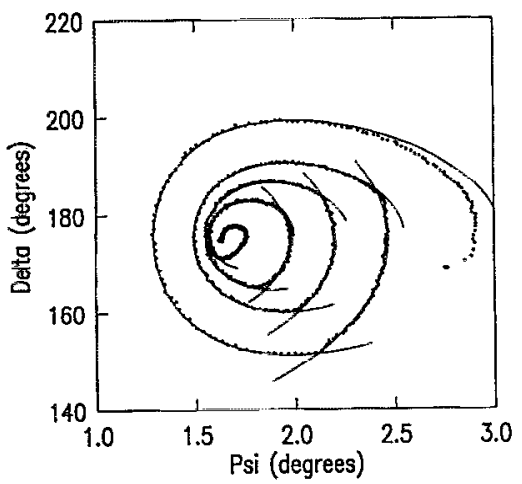

FIG. 4. The $\Psi-\Delta$ contour as measured during RIE of a Si/SiGe superlattice structure. The lines represent the simulations, and the points the measurements.

as the real part is set. Using the real part of the refractive index and the thickness as independent parameters, the ellipsometric equations can be solved numerically.

To illustrate this, we have analyzed the $\Psi-\Delta$ data measured during the RIE of a superlattice structure consisting of five layers of $50-60 \mathrm{~nm} \mathrm{SiGe,} \mathrm{separated} \mathrm{by} 20-\mathrm{nm}$-thick layers of Si. Figure 3 shows a secondary ion-mass spectrometry depth profile of the investigated superlattice. The Ge concentration of the SiGe layers varies from 2 to 14 at. \%. The $\Psi-\Delta$ plot obtained during RIE of this sample is shown in Fig. 4. The points represent the measurement, and the lines represent simulations based on homogeneous films. For clarity, the simulations were extended beyond the individual film boundaries. The refractive indices used for the simulations were taken from Figs. 2(a) and 2(b).

It is possible to perform the analysis of RIE/ ellipsometry raw data on a point-to-point basis using an automatic analysis program. The thickness etched away between two adjacent data points is about $0.1 \mathrm{~nm}$, and the refractive index can safely be assumed constant throughout this depth. A numeric procedure is used to analyze each set of two adjacent points in terms of a layer thickness and a refractive index, which corresponds to a germanium concentration. If all pairs of adjacent measurement points are analyzed in that way, and if all the thicknesses of the thin layers are added consecutively, then a profile of the germanium concentration as a function of depth can be obtained. The results and the numerical and experimental details of this inversion procedure, as well as the details of the necessary calibration routincs, will be published elsewhere. ${ }^{10}$ The calibration deals with the determination of the angle of incidence, the effect of surface modification (reaction layer, damaging, roughening), and window birefringence.

In Fig. 5, a representation is given of a Ge concentration depth profile as obtained with the inversion of the ellipsometry equations described above. A comparison of Figs. 3 and 5 shows that although the SIMS and RIE/ ellipsometry results for the Ge depth profiles agree reasonably well in terms of both the Ge concentrations and the depth of the SiGe layers, there are systematic differences. For RIE/ellipsometry the interfaces between $\mathrm{SiGe/Si}$ layers are sharp $(\leqslant 1 \mathrm{~nm})$. In SIMS, they are smeared out and

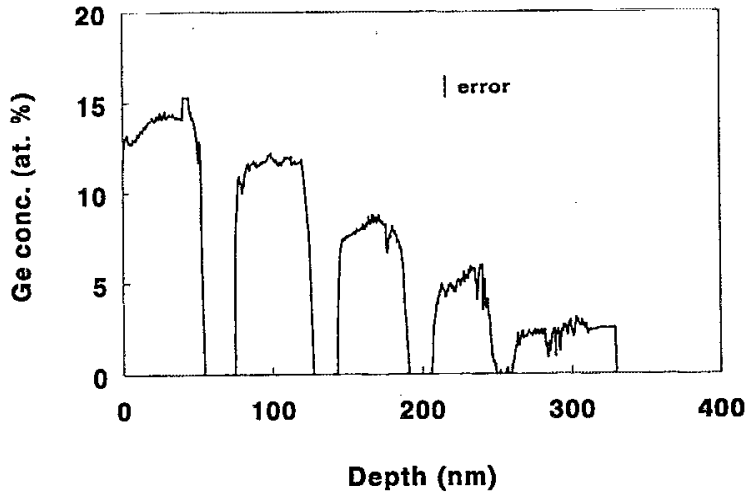

FIG. 5. The germanium content as a function of depth for a $\mathrm{SiGe} / \mathrm{Si}$ superlattice structure as determined by RIE/ellipsometry.

somewhat wider. Measurement of the layer thicknesses and the depth of the interfaces from the sample surface by transmission electron microscopy has reproduced the RIE/ellipsometry results. The peak Ge concentration of each SiGe layer indicated by SIMS is by $\approx 1 \%$ lower than found by RIE/ellipsometry. The source of this discrepancy is at this time not understood, but may be due to transient effects in the secondary ion yield in SIMS of thin SiGe layers. ${ }^{12}$ For thick layers, good agreement between the two techniques was found.

To conclude, the complex refractive index at $632.8 \mathrm{~nm}$ of strained epitaxial $\mathrm{SiGe}$ films on $\mathrm{Si}$ substrates has been determined as a function of the Ge concentration using in situ ellipsometry during reactive ion etching. Using the relation between the real and imaginary part of the refractive index and the Ge concentration, the ellipsometric data can be inverted, yielding for each homogeneous layer the thickness of that layer and its $\mathrm{Ge}$ concentration. In this way, a depth profile of the Ge concentration in the investigated sample can be obtained.

${ }^{1}$ R. People, IEEE J. Quantrum Electron. QE-22, 1696 (1986).

${ }^{2}$ G. L. Patton, J. H. Comfort, B. S. Meyerson, E. F. Crabbé, G. J. Scilla, E. de Frésart, J. M. C. Stork, J. Y.-C. Sun, D. L. Harame, and J. N. Burgharz, IEEE Electron Dev. Lett. 11, 171, (1990).

${ }^{3}$ B. S. Meyerson, Appl. Phys. Lett. 48, 797 (1986); E. de Frésart and G. W. Rubloff, IBM Tech. Discl. Bull. 31, 268 (1989).

${ }^{4}$ R. Braustein, A. R. Moore, and F. Herman, Phys. Rev. 109, 695 (1958); J. Humlicek, M. Garriga, M. I. Alonso, and M. Cardona, J. Appl. Phys. 65, 2827 (1989).

${ }^{5}$ R. M. A. Azzam and N. M. Bashara, Ellipsometry and Polarized Light (North Holland, Amsterdam, 1987).

${ }^{\circ}$ D. E. Aspnes and A. A. Studna, Phys. Rev. B 27, 985 (1983).

'J. A. Freeouf, J. C. Tsang, and S. S. Iyer, Phys. Rev. Lett. 64, 315 (1990).

${ }^{8}$ P. S. Hauge and F. H. Dill, Opt. Commun. 14, 431 (1975).

${ }^{4}$ B. S. Meyerson, K. J. Uram, and F. K. LeGoues, Appl. Phys. Lett. 53, 2555 (1988).

${ }^{10}$ G. M. W. Kroesen, G. S. Oehrlein, E. de Frésart, and M. Haverlag (unpublished).

${ }^{11}$ J. Humlicek, M. Garriga, M. I. Alonso, and M. Cardona, J. Appl. Phys. 65, 2827, (1989).

${ }^{12}$ G. J. Scilla (unpublished). 